\title{
Ефективність застосування алгоритму фізичної терапії осіб після тотального ендопротезування кульшового суглоба
}

\author{
Анна Бойко, Катерина Колиушко
}

Національний університет фізичного виховання і спорту України, Київ, Україна

Анотація. У статті подано оцінку ефективності впровадження алгоритму фізичної терапії пацієнтів після тотального ендопротезування кульшового суглоба на амбулаторному етапі відновлення. 3 огляду на те що до основних ускладнень після ендопротезування кульшового суглоба належать стійкі порушення його функціональності, обмеження мобільності та активності пацієнта у виконанні щоденної діяльності значно знижують і погіршують якість життя. Мета. Оцінити ефективність застосування алгоритму фрізичної терапії пацієнтів після тотального ендопротезування кульшового суглоба у 3-4-й фазі відновного процесу. Методи. Теоретичні, соціологічні, клінічні, математичної статистики. Результати. У дослідженні брали участь 37 осіб 56,1 $\pm 8,2$ року після тотального ендопротезування кульшового суглоба у 3-4-й фразі відновного процесу, яких було розподілено на основну та групу порівняння. При первинному обстеженні було виявлено, що у більшості пацієнтів спостерігалися знижені показники амплітуди рухів у суглобах, сили м'язів в ураженій кінцівці та погіршення їх мобільності. Застосування алгоритмізованого фрізіотерапевтичного втручання для зазначених осіб базувалося на сучасних підходах: проблемно-орієнтований, пацієнт-центрований, мультидисциплінарний та комплексний. Алгоритм фізичної терапії в основній групі пацієнтів включав засоби і методи, які умовно було поділено на чотири компоненти: терапевтичні вправи (додатково тренування ходьби та переміщень), мануальна терапія (масаж, пасивні рухи, постізометрична релаксація); апаратна фізіотерапія (процедури електроміостимуляції); рекомендації зі щоденної активності та мобільності. Для пацієнтів групи порівняння застосовували стандартні реабілітаційні заходи. При повторному обстеженні у результаті застосування алгоритму реабілітаційних заходів було виявлено достовірну позитивну динаміку на рівнях структури, фуннкції і діяльності та участі за МКФ у пацієнтів обох груп, проте в основній групі більшість зазначених показників була достовірно кращою.

Ключові слова: кульшовий суглоб, фрізична терапія, алгоритм, відновний процес.

\section{Anna Boyko, Kateryna Koliushko}

\section{THE EFFECTIVENESS OF USING PHYSICAL THERAPY ALGORITHM FOR PATIENTS AFTER TOTAL HIP ARTHROPLASTY}

Abstract. The article evaluates the effectiveness of introducing physical therapy algorithm for patients after total hip arthroplasty at the outpatient stage of recovery. Given that the main complications after hip arthroplasty include persistent violations of its functionality, limited mobility and activity of the patient in performing daily activities significantly reduce and worsen the quality of life. Objective. To evaluate the effectiveness of physical therapy algorithm for patients after total hip arthroplasty in the 3-4th phase of the recovery process. Methods. Theoretical, sociological, clinical, mathematical statistics. Results. The study involved 37 persons aged $56.1 \pm 8.2$ years after total hip arthroplasty in the 3-4th phase of the recovery process, who were divided into the main and comparison group. Initial examination revealed that most patients had reduced range of motion in the joints, muscle strength in the affected limb, and impaired mobility. The application of algorithmic physiotherapy intervention for these patients was based on modern approaches: problem-oriented, patient-centered, multidisciplinary and complex. The algorithm of physical therapy in the main group included means and methods, which were conditionally divided into four components: therapeutic exercises (additional walking and movement training), manual therapy (massage, passive movements, postisometric relaxation); instrumental physiotherapy (electromyostimulation procedures); recommendations for daily activity and mobility. Standard rehabilitation measures were used for patients of the comparison group.

Boyko A., Koliushko K. The effectiveness of using physical therapy algorithm for patients after total hip arthroplasty. Theory and Methods of Physical education and sports. 2021; 1: 19-23 DOI: 10.32652/tmfvs.2021.1.19-23
Бойко А., Колиушко К. Ефективність застосування алгоритму фрізичної терапії осіб після тотального ендопротезування кульшового суглоба. Теорія і методика фрізичного виховання і спорту. 2021; 1 19-23

DOI: 10.32652/tmfvs.2021.1.19-23
Вступ. Значна поширеність захворювань, травм, пошкоджень кульшового суглоба (KC), 3 огляду на його анатомо-біомеханічні, фрізіологічні особливості, належать до найбільш складних та тривалих патологій опорно-рухового апарату [2, 6, 10, 11]. Одним із перспективних методів лікування і часто єдиним способом відновлення функціональних можливостей кульшового суглоба є його ендопротезування - сучасний ефективний високотехнологічний метод хірургічного лікування уражень різної етіології, який полягає у заміні пошкодженого суглоба на штучний ендопротез. Це оперативне втручання сьогодні перейшло 3 категорії унікальних операцій в категорію звичайних планових хірургічних втручань і $є$ «золотим стандартом» лікування [3, 10, 15].

За даними епідеміологічних досліджень, у різних країнах річна потреба проведення процедури ендопротезування становить 500-1000 на 1 млн населення, що у перерахунку на населення України - 25-40 тис. оперативних втручань на рік. За даними експертної групи В003, в останні роки у світі виконується понад 1 млн 500 тис. операцій 3 тотальних ендопротезувань (ТЕП) і ця цифрра щороку зростає [3, 4, 9]. За прогнозами, протягом наступного десятиліття кількість первинних ТЕП КС істотно зросте: попит на це оперативне втручання прогнозовано збільшиться на 174\% до 2030 р. [13].

Проте тільки хірургічного лікування недостатньо для відновлення працездатності оперованої нижньої кінцівки, активності у виконанні побутових дій, самообслуговуванні та професійних обов'язків. Проблема відновлення функціонального стану нижньої кінцівки та активності у повсякденному житті на сьогодні ще далека від остаточного вирішення. Важливе значення мають фрізіотерапевтичні заходи $[5,9]$. 
Re-examination as a result of the application of the algorithm of rehabilitation measures revealed significant positive dynamics at the levels of structure, function and activity and participation in IFF in patients of both groups, however in the main group most of these indices were significantly better

Keywords: hip joint, physical therapy, algorithm, recovery process.

Фізична терапія (ФТ) після ТЕП КС $€$ невід'ємною складовою відновного процесу і входить до стандартів лікування патологій кульшового суглоба. Ії̈ метою є максимальна функціональність та незалежність пацієнта, а також мінімізація ускладнень та покращення рівня якості життя. Вагомим аргументом, який зумовлює необхідність розробки максимально ефективного та чіткого алгоритму ФТ для осіб після ТЕП КС, є поступовий перехід до страхової медицини та значне скорочення термінів перебування пацієнтів в умовах стаціонарного лікування [7, 9, 15]. За сучасними поглядами, однією з основних цілей ФТ та невід'ємною її складовою має бути не лише моторне відновлення оперованої нижньої кінцівки, а перш за все встановлення фізіологічного стереотипу руху відносно щоденної діяльності пацієнта, його активності та участі, яке має проводитися за чітким алгоритмом [1, 4]. Тобто, алгоритм ФТ в осіб після тотального ендопротезування кульшового суглоба, розроблений у відповідності із сучасними підходами, заснованими на базі доказової медицини та МКФ, є запорукою максимально успішного та швидкого повернення пацієнта до повноцінного та якісного життя.

Мета дослідження - оцінити ефективність застосування алгоритму фізичної терапії у пацієнтів після ендопротезування кульшового суглоба у 3-4-й фазі відновного процесу.

Методи дослідження: теоретичний аналіз й узагальнення даних науковометодичної літератури, документальних матеріалів, Інтернет-джерел. Соціологічні та клінічні методи дослідження були класифіковані за доменами МКФ. На рівні структури і функції за МКФ використовували: контентаналіз медичних карт для виявлення інформації про вік, стать пацієнтів, клінічний діагноз, методи проведеного лікування, хірургічні втручання, супутні захворювання, перебіг післяопераційного періоду, професійну діяль- ність. Для виявлення ступеня виразності больового синдрому використовували візуально-аналогову шкалу болю (ВАШ). Ступінь вихідного стану м'язів стегна, їх силу встановлювали на підставі дослідження м'язової сили пошкодженої кінцівки за допомогою електротензодинамометрії; методику гоніометрії проводили для оцінки зміни амплітуди руху в суглобі. На рівні діяльності та участі за МКФ було обрано шкалу Harris Hip Score для оцінювання цільового компонента МКФ (оцінка ффункціонального стану кульшового суглоба). Використовували методи математичної статистики, оцінювання результатів проводили за стандартними методиками.

Дослідження виконано відповідно до плану НДР Національного університету фрізичного виховання і спорту України на 2016-2020 рр. за темою 4.2. «Організаційні та теоретико-методичні основи фрізичної реабілітаціі осіб різних нозологічних, профресійних та вікових груп» (номер держреєстрації 0116U001609).

Результати дослідження та їх обговорення. Дослідно-експерементальна робота проходила на базі Центру ортопедичної реабілітації «Майстерня руху», до участі в якій було залучено 37 осіб після ТЕП КС у 3-4-й фаз відновного процесу (з 6-го тижня після операції), яких було розподілено на основну (ОГ) та групу порівняння (ГП) ( $\mathrm{n}=19$ та $\mathrm{n}=18$ відповідно). Середній вік пацієнтів - 56,2 \pm 8,7 року.

Науково обґрунтувано й розроблено алгоритм ФТ осіб після ТЕП КС на амбулаторному етапі у 3-4-й фазах відновного процесу відповідно до усіх сучасних вимог, що описує покрокову послідовність роботи фрізичного терапевта для максимально високої ефективності терапевтичного втручання та здійснено оцінку його ефективності. Спеціально розроблений алгоритм включає такі кроки:

- 1-й - первинна оцінка функціонального статусу пацієнта/клієнта та визначення його проблем;
- 2-й - планування втручання (постановка цілей, підбір засобів та методів ФТ);

- 3-й - реалізація втручання (обсяг та доцільність застосування кожного компонента ФТ, що визначається, виходячи з проблем і потреб пацієнта);

- 4-й - оцінка есрективності терапевтичного втручання (проводиться відповідно до обраних критеріїв ефективності на етапі планування втручання).

Запропонований нами алгоритм фізичної терапії пацієнтів після тотального ендопротезування кульшового суглоба у 3-4-й фазі відновлення розроблено 3 позицій сучасного проблемно-орієнтованого, пацієнтцентрованого та мультидисциплінарного підходів МКФ [8], а також комплексного, що забезпечують максимально повне та швидке відновлення активності та участі осіб, які зазнали медичного втручання. Робота з позиції проблемно-орієнтованого підходу дозволила визначити проблему пацієнта та ступінь її впливу на якість життя, а, отже, визначити основні напрями ФТ та оптимізувати підбір засобів та методів втручання. Робота 3 позиції мультидисциплінарної допомоги дозволила забезпечити ефективне та всебічне оцінювання пацієнта та залучити його до процесу відновлення як центральну фрігуру, а також ефективно координувати роботу всіх членів мультидисциплінарної команди для досягнення цілі/запиту. Комплексний підхід втручання з ФТ дав змогу використати всі доступні засоби та методи ФТ для забезпечення максимально швидкого та повного відновлення пацієнтів після ТЕП КС.

Підбір засобів та методів ФТ здійснюється, базуючись на пацієнторієнтованому підході, який передбачає відповідність засобу ФТ проблемі пацієнта [10]. Для зручності планування втручання ФТ осіб після ТЕП КС у спеціально розробленому алгоритмі $\epsilon$ умовний поділ на чотири компоненти: терапевтичні вправи (в тому числі тренування ходьби та переміщень), мануальна терапія (масаж, мобілізація суглобів у вигляді виконання пасивних рухів для покращення їх діапазону та зниження больового синдрому, а також методика постізометричної релаксації - для усунення спазму м'язів стегна); апаратна фрізіотерапія (проце- 


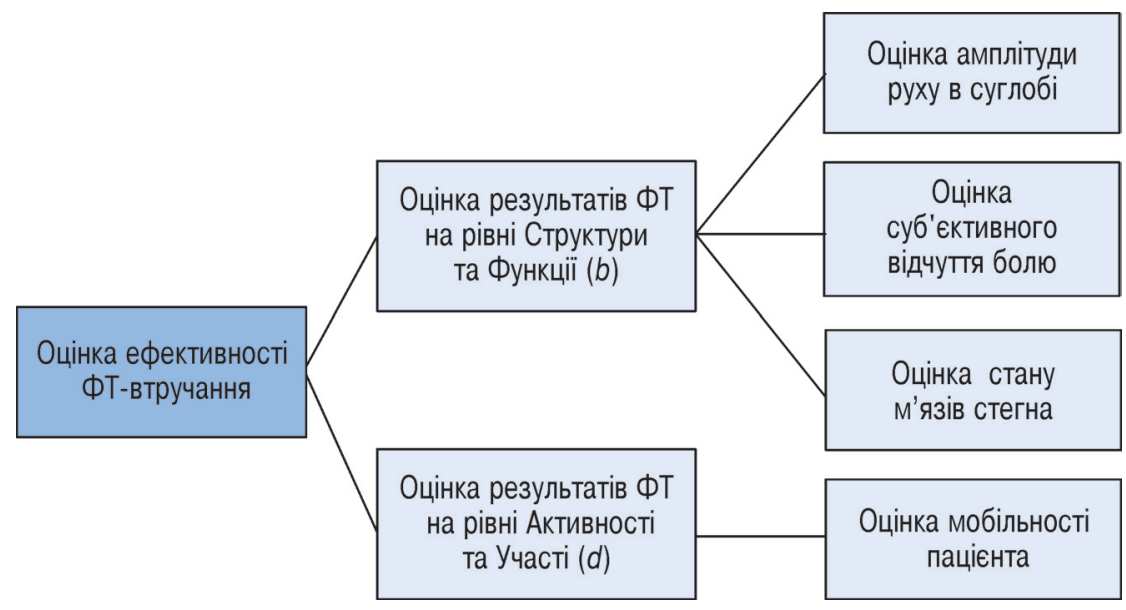

Рисунок 1 - Критерії есрективності втручання з фрізичної терапії у осіб після тотального ендопротезування кульшового суглоба

дури електроміостимуляції сідничної групи м'язів та чотириголового м'яза стегна 3 метою стимуляції обмінних і регенеративних процесів та зміцнення м'язів оперованого стегна); рекомендації до щоденної активності та мобільності (розроблені рекомендаційні пам'ятки для пацієнтів з правилами запобігання вивиху ендопротеза у вигляді друкованих матеріалів, а також рекомендації до щоденної активності).

Як критерії ефективності терапевтичного втручання було обрано шкалу Harris Hip Score для оцінювання цільового компонента МКФ для даного контингенту осіб - Активності та Участі; методика гоніометрії для оцінювання зміни амплітуди руху в суглобі, оцінювання суб'єктивного відчуття болю за ВАШ та елетротензодинамометрія для оцінювання стану м'язів стегна за компонентами Структура та Функція. Сукупність цих методик дозволила повноцінно оцінити ефективність розробленого алгоритму ФТ осіб після ТЕП КС, виходячи з позицій МКФ. Схематично обрані критерії ефрективності втручання наведено на рисунку 1 .

Загальна характеристика тематичних хворих обох груп виявила їх репрезентативність та однорідність, що дозволило об'єктивно порівнювати результати відновлення у цих групах і робити висновки про ефективність розробленого алгоритму ФТ. Вихідні показники досліджуваних параметрів у пацієнтів ОГ та ГП статистично значуще не відрізнялися $(p>0,05)$.
Для визначення есрективності розробленого алгоритму ФТ осіб після ТЕП КС проводили повторне дослідження після фізіотерапевтичного втручання. Повторне оцінювання проходило за тими самими методиками, в тих самих умовах, що і до впровадження алгоритму ФТ.

Оцінювання результатів дослідження на рівні Структури та Функції (b). Оцінювання амплітуди руху в суглобі методом гоніометрії. Шисрр МКФ. b7100 Рухливість одного суглоба.

За результатами статистичного аналізу отриманих показників гоніометрії (табл. 1) було виявлено: у пацієнтів ОГ показники флексії у КС поступово збільшувалась 3 69,3 $\pm 1,6^{\circ}$

Т а б л и ц я 1. Показники гоніометрії кульшового суглоба до та після проведення втручання з фрізичної терапії

\begin{tabular}{|c|c|c|c|}
\hline \multicolumn{4}{|c|}{ Значення показників флексії стегна, град } \\
\hline \multicolumn{2}{|c|}{ Основна група $(n=19)$} & \multicolumn{2}{|c|}{ Група порівняння ( $=18)$} \\
\hline До проведення & Після проведення & До проведення & Після проведення \\
\hline $\bar{x} \pm S$ & $\bar{x} \pm S$ & $\bar{x} \pm S$ & $\bar{x} \pm S$ \\
\hline $63,9 \pm 1,6^{\circ}$ & $92,5 \pm 1,4^{\circ *}$ & $64,4 \pm 1,4^{\circ}$ & $78,6 \pm 1,7^{\circ *}$ \\
\hline \multicolumn{4}{|c|}{ Значення показників екстензії стегна, град } \\
\hline \multicolumn{2}{|c|}{ Основна група $(n=19)$} & \multicolumn{2}{|c|}{ Група порівняння (n = 18) } \\
\hline До проведення & Після проведення & До проведення & Після проведення \\
\hline $\bar{x} \pm S$ & $\bar{x} \pm S$ & $\bar{x} \pm S$ & $\bar{x} \pm S$ \\
\hline $2,4 \pm 1,4^{\circ}$ & $10,9 \pm 0,7^{\circ *}$ & $2,2 \pm 1,6^{\circ}$ & $6,3 \pm 1,2^{\circ *}$ \\
\hline
\end{tabular}

Примітка. * - статистично достовірна різниця показників після втручання з ФТ порівняно 3 вихідними даними $(\mathrm{p}<0,05)$ $(\mathrm{x} \pm \mathrm{S})$, що становило 57,8 \% норми до $92,5 \pm 1,4^{\circ}$ після проведення втручання, $77,1 \%$ норми, тобто зросли у 1,5 раза $(p<0,05)$. У пацієнтів ГП ці показники змінилися $368,4 \pm 1,4^{\circ}$ (57 \% норми) до 79,6 $\pm 1,7^{\circ}$ (66,3 \% норми), тобто зросли лише у 1,2 раза $(p<0,05)$.

У пацієнтів ОГ показник екстензії під час первинного оцінювання становив $-2,4^{\circ} \pm 1,2^{\circ}(x \pm S)$, після проведення втручання $-10,9 \pm 0,7^{\circ}$, тобто зріс у 4,5 раза. У пацієнтів ГП відповідний показник зріс з 2,2 $\pm 1,6^{\circ}$ до $6,3 \pm 1,2^{\circ}$, тобто лише у 2,7 раза $(p<0,05)$.

Оцінювання вихідного стану м'язів стегна за результатами дослідження електротензодинамометрії (m.extensor, m.rec.femoris). Шифрр за МКФ: b7300 Сила ізольованих м'язів і м'язових груп.

За даними, порівняльного аналізу отриманих результатів досліджень сили м'язів стегна після втручання ФТ (табл. 2) у пацієнтів ОГ динаміка відновного процесу має більш позитивне значення, ніж у пацієнтів ГП: сила фрлексорів стегна оперованої кінцівки вища у 2,3 раза, сила екстензорів - у 2,7 раза порівняно з вихідними даними, і становила відповідно 96,3 \% та 98,6 \% сили фрлексорів та екстензорів здорової кінцівки. У ГП ці показники зросли у 1,6 раза (сила фрлексорів 
Т а б л и ц я 2. Показники моментів сили м'язів кульшового суглоба пацієнтів до та після проведення втручання з фрізичної терапії

\begin{tabular}{|c|c|c|c|c|}
\hline \multirow{4}{*}{ Кінцівка } & \multicolumn{4}{|c|}{ Значення показників сили флексорів стегна, Нм } \\
\hline & \multicolumn{2}{|c|}{ Основна група ( $n=19)$} & \multicolumn{2}{|c|}{ Група порівняння ( $\mathrm{n}=18$ ) } \\
\hline & До проведення & Після проведення & До проведення & Після проведення \\
\hline & $\bar{x} \pm S$ & $\bar{x} \pm S$ & $\bar{x} \pm S$ & $\bar{x} \pm S$ \\
\hline Оперована & $40,9 \pm 3,5$ & $95,1 \pm 2,5^{\star}$ & $41,1 \pm 4,1$ & $64,2 \pm 2,0 *$ \\
\hline Іेнтактна & $56,5 \pm 2,6$ & $98,8 \pm 1,6^{*}$ & $55,1 \pm 2,4$ & $72,7 \pm 1,8^{*}$ \\
\hline \multirow{4}{*}{ Кінцівка } & \multicolumn{4}{|c|}{ Значення показників моментів сили екстензорів стегна, Нм } \\
\hline & \multicolumn{2}{|c|}{ Основна група $(n=19)$} & \multicolumn{2}{|c|}{ Група порівняння ( $=18)$} \\
\hline & До проведення & Після проведення & До проведення & Після проведення \\
\hline & $\bar{x} \pm \mathbf{S}$ & $\bar{x} \pm S$ & $\bar{x} \pm S$ & $\bar{x} \pm S$ \\
\hline Оперована & $36,2 \pm 2,1$ & $96,6 \pm 2,4^{*}$ & $35,9 \pm 2,5$ & $68,2 \pm 1,4^{*}$ \\
\hline інтактна & $54,3 \pm 3,6$ & $98,0 \pm 2,1^{*}$ & $56,1 \pm 3,0$ & $73,5 \pm 1,4^{*}$ \\
\hline
\end{tabular}

Примітка. * - статистично достовірна різниця показників після втручання з ФТ порівняно 3 вихідними даними $(p<0,05)$.

Т а б л и ц я 3. Показник суб'єктивного відчуття болю пацієнтів за ВАШ до та після проведення втручання з фрізичної терапії

\begin{tabular}{|c|c|c|c|}
\hline \multicolumn{3}{|c|}{ Показник суб'єктивного відчуття болю, бали } \\
\hline \multicolumn{2}{|c|}{ Основна група $(\mathrm{n}=19)$} & \multicolumn{2}{|c|}{ Група порівняння $(\mathrm{n}=18)$} \\
\hline До проведення & Після проведення & До проведення & Після проведення \\
\hline $\bar{x} \pm \mathrm{S}$ & $\bar{x} \pm \mathrm{S}$ & $\bar{x} \pm \mathrm{S}$ & $\bar{x} \pm \mathrm{S}$ \\
\hline $3,1 \pm 1,0$ & $1,2 \pm 0,6^{*}$ & $3,2 \pm 0,9$ & $2,3 \pm 0,7^{*}$ \\
\hline
\end{tabular}

Примітка. * - статистично достовірна різниця показників після втручання з ФТ порівняно 3 вихідними даними $(p<0,05)$

Т а б л и ц я 4. Показники функції кульшового суглоба за Harris Hip Score до та після проведення втручання з фрізичної терапії

\begin{tabular}{|c|c|c|c|}
\hline \multicolumn{3}{|c|}{ Показники функціональності кульшового суглобу за ННS } \\
\hline \multicolumn{2}{|c|}{ Основна група ( $\mathrm{n}=19)$} & \multicolumn{2}{|c|}{ Група порівняння $(\mathrm{n}=18)$} \\
\hline До проведення & Після проведення & До проведення & Після проведення \\
\hline $\bar{x} \pm \mathrm{S}$ & $\bar{x} \pm \mathrm{S}$ & $\bar{x} \pm \mathrm{S}$ & $\bar{x} \pm \mathrm{S}$ \\
\hline $67,9 \pm 2,4$ & $87,65 \pm 2,2^{*}$ & $68,3 \pm 3,3$ & $72,9 \pm 2,1^{*}$ \\
\hline
\end{tabular}

Примітка. * - статистично достовірна різниця показників після втручання з ФТ порівняно 3 вихідними даними $(p<0,05)$

стегна) та 1,9 раза (сила екстензорів стегна) $(\mathrm{p}<0,05)$.

Оцінювання суб'єктивного відчуття болю за візуально-аналоговою шкалою болю (ВАШ). Шифр МКФ: b28016 Біль у суглобах.
Отримані результати за ВАШ (табл. 3) дають підстави говорити про зниження рівня больових відчуттів у пацієнтів ОГ і ГП. Показник суб'єктивного відчуття болю, засріксований на етапі первинного оціню- вання пацієнтів ОГ та ГП не мав статистично значущої різниці за середніми показниками $(p>0,05)$ і становив $3,1 \pm 1,0$ бал $(x \pm \mathrm{S})$ у ОГ та $3,2 \pm 0,9$ бала $(X \pm S)$ у ГП.

Різниця зареєстрованих наприкінці відновної терапії показників була статистично значущою $(p<0,05)$ : показники суб'єктивного больового відчуття пацієнтів ОГ мали більш позитивну динаміку, ніж показники пацієнтів ГП, і після втручання становили 1,2 \pm 0,6 бала $(x \pm S)$ і 2,3 \pm 0,7 бала $(x \pm \mathrm{S})$ відповідно.

Оцінювання результатів дослідження на рівні Активності та Участі (d). Оцінювання фрункціонального стану кульшового суглоба проводили за шкалою Harris Hip Score. Шифр за МКФ: d2303 Управління рівнем власної активності. За допомогою шкали визначали ефективність втручання 3 ФТ відповідно до розробленого алгоритму шляхом оцінювання рівня мобільності пацієнта у просторі, a, отже рівня його активності та участі.

За сумою балів за чотирма категоріями, а саме «Біль», «Функція», «Відсутність деформації» та «Амплітуда рухів», функціональний стан оперованого КС після втручання становив у середньому 87,65 $\pm 2,2$ бала в ОГ та $72,9 \pm 2,1$ бала в ГП: різниця між результатами пацієнтів ОГ та ГП становила майже 15 балів. Результати показників функціональності стегна за Harris Hip Score мобільність пацієнтів ОГ було оцінено як «добрі», а ГП - як «задовільні» (табл. 4).

За даними гоніометрії, електротензодинамії, оцінювання суб'єктивного відчуття болю за ВАШ та функції кульшового суглоба за Harris Hip Score можна зробити висновок, що застосування запропонованого алгоритму ФТ осіб після ТЕП КС привело до кращих функціональних результатів втручання у пацієнтів ОГ порівняно з пацієнтами ГП, які займалися за стандартною програмою.

Дискусія. Прогрес оперативних технологій зробив заміну кульшового суглоба оперативним втручанням століття. Проте профрілі пацієнтів, які потребують ТЕП КС, змінюються: як мінімум, «молодшають» причини, що призводять до ТЕП КС [12, 14], що породжує проблему пошуку та адаптації стандартизованих алгоритмів фі- 
зичної терапії після ТЕП КС у зв'язку 3 підвищеними функціональними вимогами та високими цілями пацієнтів.

Під час підготовки до проведення даного дослідження в процесі аналізу літературних джерел не вдалося знайти уніфікованих протоколів та алгоритмів ФТ після ТЕП КС, а також національних чи міжнародних стандартів ведення таких пацієнтів, що значно ускладнює роботу ФТ з пацієнтом/клієнтом даного профрілю. Особливо проблема стосується 3-4-ї фрази відновного процесу, оскільки ранній післяопераційний період описано та стандартизовано на рівні окремих клінік.

Розроблений нами алгоритм ФТ після ТЕП КС у 3-4-й фразі відновного процесу базується на аналізі зарубіжних та вітчизняних підходів до ФТ осіб після ТЕП КС. Він покликаний вирішити проблему алгоритмізованої роботи з особами після даного оперативного втручання і дозволяє оптимізувати призначення фізіотерапевтичних заходів, які спрямовані на відновлення втрачених функцій кінцівки.

Проте питання національного/міжнародного стандарту ведення таких пацієнтів залишається відкритим.

Висновки. Представлений фактичний матеріал підтверджує дані ефективності впливу запропонованого алгоритму фрізичної терапії на відновлення функції ендопротезованої кінцівки. Виявлено, що під впливом компонентів розробленого алгоритму фрізичної терапії осіб після ТЕП КС у пацієнтів основної групи зареєстровані кращі результати з боку всіх оцінених показників: болю, амплітуди руху, сили м'язів, а також оцінювання пацієнта за шкалою Harris Hip Score, порівняно з пацієнтами групи порівняння, які займалися за стандартною програмою. Це свідчить про те, що використання розробленого алгоритму ФТ осіб після ТЕП КС дозволяє досягти кращих результатів відновлення.

Перспективи подальших досліджень полягають у вивченні віддалених результатів впливу алгоритму фрізіотерапевтичного втручання.

Конфлікт інтересів. Автори заявлять, що відсутній будь-який конфлікт інтересів.

\section{ЛITEPATУPA}

1. Бабова IK, Торчинський ВП, Біла II, Май ко ВМ. Алгоритм реабілітації хворих, що потребують ендопротезування кульшового суглоба Вісник ортопедії, травматології та протезування.2010;2:30-35.

2. Вакуленко ВМ. Вывихи после тотального эндопротезирования тазобедренного сустава. Травма. 2014;15(3):47-55.

3. Васильчишин ЯМ. Удосконалена технологія ендопротезування кульшового суглоба Буковинський медичний вісник. 2014;4(72):7-12.

4. Гайко ГВ, Поляченко ЮВ, Рибачук ОІ Стан та перспективи розвитку ендопротезу вання суглобів в Україні. Вісник ортопедії, травматології та протезування. 2000; 2(27):71-2.

5. Глиняна 0, Попадюха Ю. Алгоритм реабілітації після первинного ендопротезування кульшового суглоба. Психологія та педагогіка. 2011;8:30-32.

6. Заморський ТВ. Відновлення після ендопротезування кульшового суглоба [монографія]. Рівне: Волинські обереги; 2011: 92с.

7. Клінічний протокол первинного ендопротезування кульшового суглоба. Ортопедия, травматология и протезирование. 2015:2:137-41. DOI: http://dx.doi.org/10.15674/0030-598720152137-141

8. Міжнародна класифікація функціо нування, обмеження життєдіяльності і здоров'я: МКФ (переклад українською мовою). Всесвітня організація охорони здоров'я, Женева, 2001.

9. Оріховська А, Федоренко С, Колиушко К Сучасні підходи фрізичної терапії осіб після тотального ендопротезування кульшового сугло ба. Теорія і методика фрізичного виховання спорту. 2020;(1):81-6.

10. Aprato A, Baroni $C$ and Massè C. Rehabbilitation after total hip arthroplasty: Is there an evidence? Phys Med Rehabil Res. 2018;3(4):1-2.

11. Coulter CL, Scarvell JM, Neeman TM Smith PN (2013) Physiotherapist-directed rehabiliimprove strength, gait speed and cadence afte elective total hip replacement: A systematic review. J Physiother. 2017;59:219-26.

12. Guimarães Barros AA, Cardoso Mendes $\mathrm{CH}$, Frois Temponi E, Costa L, et al. Efficacy evaluation of a protocol for safe hip surgery (total hip arthroplasty). Rev Bras Ortop. 2017;52(1): 29-33.

13. Kurtz SM, Ong K, Lau E, Mowat F, Halpern M. Projections of primary and revision hip and knee arthroplasty in the United States from 2005 to 2030. J Bone Joint Surg Am. 2007;89(4):780-5.

14. Rehabilitation Protocol: Total Hip Arthroplasty (THA). Lahey Hospital \& Medical Center. 2014.

15. Spalević M, Milenković S, Kocić M, Stanković I, Dimitrijević L, Živković V et al. Tota tation exercises in the outpatient or home setting

hip replacement rehabilitation: results and dilemmas. Acta Medica Medianae. 2018;57(1):48-53.

\section{LITERATURE}

1. Babova IK, Torchynskyi VP, Bila II, Mayko VM. Algorithm for rehabilitation of patients in need of hip arthroplasty. Visnyk ortopedii, travmatolohii ta prorezuvannia.2010;2:30-35.

2. Vakulenko VM. Dislocations after total hip arthroplasty. Travma. 2014;15(3):47-55.

3. Vasylchyshyn IM. Improved hip arthroplasty. Bukovinskyi medychnyi visnyk. 2014;4(72):7-12.

4. Hayko HV, Poliachenko IV, Rybachuk OI. State and prospects of joint arthroplasty development in Ukraine. Visnyk ortopedii, travmatolohii ta prorezuvannia. 2000; 2(27):71-2.

5. Hlyniana 0, Popadiukha I. Rehabilitation algorithm after primary hip arthroplasty. Psykholohiia ta pedahohika. 2011;8:30-32.

6. Zamorskyi TV. Recovery after hip arthroplasty [monograph]. Rivne: Volynski oberehy 2011: $92 p$

7. Clinical protocol of primary hip arthro plasty. Orthopedics, traumatology and prosthetics. 2015;2:137-41. DOl:http://dx.doi.org/ 10.15674/0030-598720152137-141

8. International Classification of Functioning Restriction of Life and Health: IFF. WHO, Geneva, 2001.

9. Orikhovska A, Fedorenko S, Kolyushko K Modern approaches to physical therapy of persons after total hip arthroplasty. Teoriia i metodyka fizvykhovannia i sportu. 2020;(1):81-6.

10. Aprato A, Baroni C and Massè C. Rehabilitation after total hip arthroplasty: Is there an evidence? Phys Med Rehabil Res. 2018;3(4):1-2.

11. Coulter CL, Scarvell JM, Neeman TM, Smith PN (2013) Physiotherapist-directed rehabilitation exercises in the outpatient or home setting improve strength, gait speed and cadence after elective total hip replacement: A systematic review. J Physiother. 2017;59:219-26.

12. Guimarães Barros AA, Cardoso Mendes $\mathrm{CH}$, Frois Temponi E, Costa L, et al. Efficacy evaluation of a protocol for safe hip surgery (total hip arthroplasty). Rev Bras Ortop. 2017;52(1): 29-33.

13. Kurtz SM, Ong K, Lau E, Mowat F, Halpern M. Projections of primary and revision hip and knee arthroplasty in the United States from 2005 to 2030. J Bone Joint Surg Am. 2007;89(4):780-5.

14. Rehabilitation Protocol: Total Hip Arthroplasty (THA). Lahey Hospital \& Medical Center. 2014

15. Spalević M, Milenković S, Kocić M Stanković I, Dimitrijević L, Živković V et al. Total hip replacement rehabilitation: results and dilemmas. Acta Medica Medianae. 2018;57(1):48-53.

Надійшла 21.12.2020

\section{ІНФОРМАЦІЯ ПРО АВТОРІВ}

Бойко Анна Сергіївна https://orcid.org/0000-0003-4742-1585, e-mail: anetorekhovskaya1305@ gmail.com

Колиушко Катерина Вікторівна e-mail: kolyushko_katya@ukr.net

Національний університет фізичного виховання і спорту України 03150, Київ, вул. Фізкультури, 1

\section{INFORMATION ABOUT THE AUTHORS}

Boiko Anna https://orcid.org/0000-0003-4742-1585, e-mail: anetorekhovskaya1305@gmail.com

Kolyushko Kateryna e-mail: kolyushko_katya@ukr.net

National University of Ukraine on Physical Education and Sport

03150, Kyiv, Fizkul'tury str., 1 